\title{
Forum
}

\section{Conservation, evidence and policy}

\author{
William. M. Adams and Chris Sandbrook
}

\begin{abstract}
A growing literature argues for evidence-based conservation. This concept reflects a wider approach to policy-making and follows thinking in medicine, in which rigorous, objective analysis of evidence has contributed to widespread improvements in medical outcomes. Clearly, conservation decisions should be informed by the best information available. However, we identify issues relating to the type and sources of evidence commonly used and the way evidence-based conservation studies frame policy debate. In this paper we discuss two issues; firstly, we ask 'what counts as evidence?' (what is meant by evidence, and what kind of evidence is given credibility). We conclude that evidence-based conservation should adopt a broad definition of evidence to give meaningful space for qualitative data, and local and indigenous knowledge. Secondly, we ask 'how does evidence count?' (the relationship between evidence and the policy-making process). We conclude that there should be greater recognition that policy-making is a complex and messy process, and that the role of evidence in policy making can never be neutral. In the light of these issues we suggest some changes to build on developing practice under the title evidence-informed conservation. The change in terminology is subtle, yet it has profound implications in that it calls for a re-positioning and re-understanding of conservation science as one source of information among many for decision-makers.
\end{abstract}

Keywords Conservation, evidence-based conservation, knowledge, policy, science-policy interface

\section{Introduction}

\footnotetext{
growing literature makes the case for evidence-based $A_{\text {conservation (e.g. Pullin \& Knight, 2001, 2003; }}$ Sutherland et al., 2004). The approach has been adopted by a number of research groups and is now supported by at least two dedicated journals (Conservation Evidence and Environmental Evidence). Evidence-based conservation is

William M. AdAms Department of Geography, University of Cambridge, Cambridge, UK

CHRIS SANDBROOK ${ }^{*}$ (Corresponding author) UNEP World Conservation Monitoring Centre, Cambridge, CB3 0DL, UK

E-mail chris.sandbrook@unep-wcmc.org

*Also at: Department of Geography, University of Cambridge, Cambridge, UK

Received 1 July 2012. Revision requested 17 October 2012.

Accepted 19 October 2012. First published online 10 May 2013
}

established as a new narrative in conservation; a set of ideas that frame a particular way of thinking as a self-evidently correct solution to a standardized set of problems (Roe, 1991; Leach \& Mearns, 1996; Adams, 2010).

The idea of evidence-based conservation reflects a broader engagement in evidence-based management and evidence-based policy. This has emerged across multiple sectors in countries such as the UK (Cabinet Office, 1999; House of Commons Science and Technology Committee, 2006) as an attempt to modernize the procedures of government and make decisions impartially and objectively, without political or value-based choices (Sanderson, 2002). In medicine in particular, rigorous, objective analysis of evidence has contributed to widespread improvements in medical outcomes (Petticrew \& Roberts, 2003; Fazey et al., 2004). Evidence-based conservation initially sought to apply the methods of evidence-based medicine to conservation (Fazey et al., 2004). However, conservation is different from medicine in several ways (Fazey et al., 2004, 2006a; Stewart et al., 2005). For example, the social-ecological systems involved in conservation are far more complex than the human bodies that are the target of most medical interventions. In response to this challenge, evidencebased conservation has developed and diversified, and standard methodologies have been defined (e.g. Pullin \& Stewart, 2006). However, our reading of the literature and our experience of the way the case for evidence-based conservation is articulated by professional conservationists in conferences, seminars, and numerous informal conversations suggests that as thinking about evidence in conservation has spread, it has become somewhat formulaic in the type and sources of evidence used, and the way evidencebased conservation frames policy debate. We find this problematic, and in this paper we discuss our concerns.

We need to clarify several points. Firstly, this is not a systematic review of evidence-based conservation, although we mention as wide a range of studies as space allows. We draw extensively on our own experience of the approach, and on listening and talking to others. Secondly, our purpose is not to attack the use of evidence in conservation: we recognize that conservation decisions need to take account of available knowledge about the processes affecting biodiversity and biodiversity loss. However, we want to promote a broader discussion of the implications of evidence-based approaches in conservation. Such discussions have taken place in other complex areas of policy such as international development, sustainability and health (Greenhalgh \& Russell, 2009; Elgert, 2010; du Toit, 2012; 
Hagen-Zanker et al., 2012). We focus on two particular questions. The first is 'what counts as evidence?', in response to which we discuss what is meant by evidence, and what kind of evidence is given credibility. The second is 'how does evidence count?', in which we explore the way in which policy decisions are informed by conservation evidence. In the following sections we explore these challenges in more detail, before concluding with a call for a transition from evidence-based conservation to evidence-informed conservation.

\section{What counts as evidence?}

A crucial question for all evidence-based policy is how to define evidence. This can be broken down into two subquestions; what kind of information is considered as evidence, and what sources of information can provide such evidence?

Evidence-based conservation reviews tend to be dominated by quantitative information. For example, the Conservation Evidence website explicitly states that for a study to be included its effects must have been monitored quantitatively' (ConservationEvidence.com, 2013). Some papers that explain an evidence-based approach to conservation do explicitly recognize that different kinds of information can provide useful evidence, including qualitative data (e.g. Sutherland et al., 2004; Pullin et al., 2009), which are included in a number of recent systematic reviews for evidence-based conservation (e.g. Brooks et al., 2006; Waylen et al., 2010). However, even where qualitative data are used, they are conventionally analysed quantitatively, using numerical scores. Thus in their study of the effect of local institutions on conservation project outcomes, Waylen et al. (2010) identified 15 explanatory variables associated with project context and design: the 'supportiveness' of local institutions was scored on a three-level ordinal variable. This is a careful and thoughtful study but it uses a highly reductionist approach to qualitative data.

The focus on quantitative data and analysis may in part reflect the analytical training of scientists and an ingrained bias towards quantitative data on the grounds that it is believed to be more rigorous, testable and hence reliable. Writing on evidence-based conservation persistently implies that qualitative data are inferior to quantitative data, and particularly to experimental studies with appropriate controls (Pullin \& Knight, 2001; Sutherland et al., 2004). For example, Stewart et al. (2005) stated that 'a major concern must be that there will rarely be sufficient good quality evidence to enable a systematic review to draw robust conclusions through quantitative and statistical analysis' (p. 276). We agree that there are certain questions that are best answered with such data. But there are many others that are best approached with qualitative methods, and which cannot be satisfactorily allocated to ordinal categories. For example, West (2005) used ethnographic methods to explain the complex reasons for failure of an integrated conservation and development project in Papua New Guinea.

What are appropriate sources of evidence for conservation? Evidence-based conservation reviews are dominated by the peer-reviewed academic literature, which itself is dominated by studies conducted by professional researchers. Attempts to marshal and review evidence rarely draw on knowledge that is informal and not recorded in websearchable literature (e.g. Pullin \& Salafsky, 2010; Segan et al., 2010). It is reasonable to assume that much of the evidence provided by the academic literature, whether quantitative or otherwise, is of a good standard, and procedures for evidence-based systematic reviews propose careful sifting of studies to ensure only those carried out with sufficient rigour are reviewed. However, it is important to note that the formal research literature is not always correct, even when ideas are widely shared. Thomas Kuhn (1962) described how scientists lock into particular forms of explanation before scientific results (and often maverick scientists) eventually overturn the paradigm. It is in the nature of science that scientists disagree, including in their interpretation of the same body of evidence. It is for this reason that, in discussing the role of scientific experts in advising policy-makers on risk, Stirling (2010) called for 'a measured array of contrasting specialist views' (p. 1030). There is an entire academic discipline, Science and Technology Studies, devoted to understanding the scientific process (Jasanoff et al., 1995) and demonstrating that the process of undertaking science cannot be separated from social and political processes of thinking and decisionmaking. The decisions taken by scientists undertaking evidence-based reviews in judging 'good knowledge' are careful but also socially constructed and vulnerable to false certainties.

What sources of evidence exist outside the formal research literature, both published and web-searchable grey literature? Two important, and sometimes overlapping, examples offer important insights for policy; indigenous knowledge, and traditional or local knowledge.

Indigenous knowledge is both a practical and epistemological challenge to western science and its claims of privileged expert judgement (Berkes, 1999). Anthropologists have criticized the conventional practice of using western scientific rationality as the benchmark against which other types of knowledge should be evaluated (e.g. WatsonVerran \& Turnbull, 1997), yet even by this narrow measure indigenous knowledge is recognized to make a potentially important contribution to conservation decision-making (Pilgrim \& Pretty, 2010). Indigenous knowledge is particularly challenging for western science because it is frequently based on world-views that do not map readily onto those 
held by most professional scientists. The potential importance of local knowledge and expertise is increasingly being recognized by conservation scientists (e.g. Sheil \& Lawrence, 2004; Fraser et al., 2006).

Traditional knowledge is defined by the International Council for Science as 'a cumulative body of knowledge, know-how, practices and representations maintained and developed by peoples with extended histories of interaction with the natural environment' (ICSU, 2002, p. 3). This category would include indigenous knowledge, but also knowledge held by a formally trained expert such as a protected area manager, or knowledge held by people who live and work in a place over time. It is knowledge derived from such personal experience that Pullin et al. (2004) suggested evidence-based approaches should replace. Thus Pullin \& Salafsky (2010) wrote about the need for science to replace 'myth and anecdote' (p. 916), citing Sutherland et al. (2004) who worried that 'much of conservation is... based on myths' (p. 306). Traditional knowledge can indeed turn out to be mistaken when issues are subjected to formal scientific analysis. But it can also give deep insights into issues affecting a problem that may be missed by scientists with a superficial contextual understanding or short-term data. There is a parallel in medicine: Krska \& Avery (2011) noted the power of direct reporting by patients of issues such as adverse reactions to drugs, even though such information is routinely dismissed by conventional healthcare professionals.

The critical point here is the nature of expertise (I. Fazey, pers. comm.). Expertise does not reside solely with scientists or professionals, even if the expertise of less qualified people is not recognized by certification (Collins \& Evans, 2002). Local people may have acquired profound 'practice-based' environmental knowledge through prolonged observation and exposure (Ingold, 2000). Such experience-based experts have much to contribute to conservation investigations and debates (Collins \& Evans, 2002), which is why it is important to 'let local voices speak' (Peterson et al., 2010, p. 9). Krueger et al. (2012) distinguished between experts and non-experts by the relevance and depth of their experience of a particular problem. Experts can be scientists or professional managers but also experienced members of the public. Fazey et al. (2006b) explored the importance of implicit experiential knowledge for wetland management but noted that it can be impossible to elicit quantitatively as it needs to be understood in the context of connected underlying values and assumptions. Thus both scientists and local lay people may be experts or novices with respect to particular problems: speaking a foreign language is an expertise but in a foreign land everybody does it (Collins \& Evans, 2007). Deciding whether the source is credible requires the judgement of the listener. Choosing what counts as evidence is a task that needs great care and strong contextual understanding.
Our own experience of conducting systematic reviews of the conservation literature has shown us how difficult it can be to incorporate and synthesize qualitative data and grey literature sources, let alone traditional and indigenous knowledge. The time and resources available force the reviewer to take practical decisions to limit the task, and only by setting tight criteria of acceptability is it possible to reduce the world of evidence to a small number of papers that can be read and from which tables can be compiled. Our concern is that much potentially valuable information is lost in this process because it is not legible to the technology of systematic review. We are not suggesting the need for better reduction or translation techniques but encourage an evidence-based conservation that promotes a pluralistic view of evidence, in which the outcome of systematic reviews of formal literature are set alongside other views of particular issues, to allow decision-makers to develop policy that relates to a broad range of insights and conclusions (cf. Stirling, 2010).

\section{How does evidence count?}

Evidence-based policy calls for decisions to be based on evidence. It is a 'policy about policy' (du Toit, 2012, p. 2). This raises the question of how evidence, however defined, counts in decision-making processes. Writing on evidencebased conservation tends to present poor decision-making as the consequence of a fairly straightforward information deficit problem, which the methods of evidence-based conservation can address by providing information to decision-makers 'in a usable format' or delivered in 'an integrated and accessible way' (Pullin \& Knight, 2003, pp. 84, 89). Some writing on evidence-based conservation acknowledges that this can be challenging. For example, Pullin et al. (2009) noted the difference between 'broad holistic questions typically posed in policy formation and narrow reductionist questions that are susceptible to scientific method' (p. 970). The relationship between evidence and policy has received a great deal of attention in the academic literature, particularly in the field of international development. This field resembles conservation in its complexity, uncertainty about the impact of policy decisions on outcomes, urgency, and the missiondriven nature of its related academic field of development studies (e.g. Roe et al., 2012).

The development literature raises some important further issues that we believe are relevant to evidencebased conservation. Firstly, the evidence-based approach implies that it is possible to determine which interventions cause particular outcomes, and thus tune policy to maximize effectiveness (du Toit, 2012). Thus Pullin et al. (2004, p. 245) noted 'ideally, decisions should be based on effectiveness of actions in achieving the objectives as 
demonstrated by scientific experiment'. In other words, policy should be based on 'what works'. As du Toit (2012) observed, the evidence-based approach can work where change is well understood and the system is small and susceptible to input-output analysis. So, in conservation, the approach is appropriate to problems that can be tightly specified (e.g. pest control, fire management or the location of bird nest-boxes). It is less easy to apply satisfactorily to the multidimensional factors and context specificity that characterize other kinds of conservation project (e.g. attempts to reduce the poverty of people living adjacent to protected areas through alternative livelihood projects). Sanderson (2002) was sceptical about the feasibility of following policy interventions through to outcomes. In the introduction to a recent book on evidence-based conservation in the Lower Mekong, Sunderland et al. (2012, p. 4) stated that 'we expected to be able to develop sets of simple metrics that would enable us to make statements about the conservation and development performance of projects. However, all of the projects that we describe... operate in the complex, messy, real world where even obtaining clarity on shared goals among such diverse stakeholders is difficult'. Pullin et al. (2009) proposed a framework for breaking up large problems into interventions that can be addressed piecemeal through evidence-based reviews. This may be effective in some cases but many conservation problems are so complex and emergent that, as with development policy, this reductionist approach runs the risk of confusing policy-makers by disguising the politics of decisions in a fog of apparently technical issues (Ferguson, 1990; Büscher, 2010).

Secondly, evidence-based policy tends to support a linear model of policy-making, in which good information fed in at one end leads to good decisions at the other (Greenhalgh \& Russell, 2009). In this view, policy-making comprises 'a series of technical steps': the selection, synthesis and critical evaluation of the best research evidence allows the best policy to be selected (Greenhalgh \& Russell, 2009, p. 308). $\mathrm{Du}$ Toit (2012) argued that in this sense evidence-based policy reflects 'a narrow and technocentrist understanding of what is involved in policy-making' (p. 8). Reality is much more complex and messy (Keeley \& Scoones, 2003). Most conservation decisions (like those in development) are not made through a process whose effectiveness is controlled by the supply of expert information but are highly political processes in which different actors struggle to influence outcomes (Sabatier \& Jenkins-Smith, 1993; Hajer, 1995; Pretty, 2002; Keeley \& Scoones, 2003). As Greenhalgh \& Russell (2009) observed, policy-making is not a matter of applying objective evidence to problems that exist 'out there' in some predetermined form, it is 'about constructing these problems through negotiation and deliberation', making 'context-sensitive choices in the face of persistent uncertainty and competing values' (p. 315).
Thirdly, evidence-based policy presents itself as neutral, when in fact it is a political project that promotes particular forms of evidence and processes of policy-making. Evidence is never neutral (it never 'speaks for itself', du Toit, 2012, p. 4) because both science and policy-making are shaped by discursive practices that allow particular observations, findings or records to count as evidence. Policy debates do not happen in a political vacuum where scientific consensus can be teased out. Policy options are expressed through the construction of narratives that 'frame' how facts are understood (Roe, 1991; Sabatier \& Jenkins-Smith, 1993; Hajer, 1995; du Toit, 2012). This framing determines what counts as evidence (see above), but also what this evidence means, who is involved in talking about the evidence, and how information about the evidence is communicated (du Toit, 2012).

Formal science and the knowledge it generates has great power as a legitimising force, and is often used as a voice of authority in environmental policy (Keeley \& Scoones, 2003; Dickson \& Adams, 2009). Evidence-based conservation attempts to extend the social authority of experimental or observational science to the process of reviewing existing knowledge. By its procedures, it privileges good scientific data, and the ideas and framing of those who create it. The legitimacy attributed to evidence derived from formal science is a powerful influence on policy that can artificially depoliticize questions that should rightfully be subject to public deliberation (Büscher, 2010; Elgert, 2010). It can also override the knowledge of others, in the process rendering mute their ability to express their rights and wishes. This power asymmetry can be particularly significant in developing countries where governance is weak and the opportunity for informed public debate is limited (Brosius, 1999; Bryant, 2002; Fairhead \& Leach, 2003).

\section{From evidence-based conservation to evidence-informed conservation?}

We have identified two sets of challenges relating to evidence-based conservation: the type and sources of evidence used, and the way evidence-based conservation frames policy debate. These suggest to us the need to think further about the practice of evidence-based conservation and its relation to policy.

Firstly, we would like to see the view of what constitutes useful evidence for conservation broaden to give more space for local and indigenous knowledge and for qualitative data. The integrated experience of individuals, or what Sanderson et al. (2002, p. 71) called 'practical wisdom' has currently under-recognized potential to contribute to understanding conservation problems. This is a pressing issue, particularly in the context of the newly established Intergovernmental Science-Policy Platform on Biodiversity and Ecosystem 
Services, which will need to establish procedures for dealing with information derived from a range of different sources (Tengö et al., 2011; Turnhout et al., 2012). This is not an impossible challenge: Raymond et al. (2010) suggested a framework for integrating local and scientific knowledge, and we encourage its adoption. We recognize that certain forms of evidence will be more appropriate than others to answer specific questions but we reject the notion of an evidence hierarchy that places quantitative and experimental studies at the top. We are concerned that in conservation the scientific training of most practitioners (and their lack of training in other forms of enquiry) leaves them vulnerable to a bias in precisely this direction. Rather, we see merits in the adoption of a matrix or typology approach that helps to identify the strengths and weaknesses of different evidence for particular problems (Petticrew \& Roberts, 2003). This approach has been applied in medicine, where it has been found particularly useful in the case of social and public health actions that do not fit neatly into the category of treatment-response interventions that are amenable to experimental and quantitative study. Many (arguably all) conservation problems are social in nature, and we find the case for this broader approach to evaluating conservation evidence convincing. There are clearly technical challenges to incorporating indigenous and local knowledge into systematic reviews and conservation practice (Raymond et al., 2010) but the importance for conservation of 'letting the locals lead' (Smith et al., 2009) and 'social learning' (Gardner, 2012) are widely noted: this sensibility needs to extend to evidence-based conservation.

Secondly, we would like to see a more informed understanding of how policy-making works and of the proper place of formal science reviews within it. Scientific procedures do not offer a 'get out of politics free' card. This is clear from cases in which the scientific evidence is unequivocal yet politicians develop policies that go against it, as in the case of the UK badger cull (Observer, 2012). Decision-makers can also excuse delays by alleging that evidence is insufficient; for example, in the delayed designation of Marine Conservation Zones in UK waters (despite a lengthy stakeholder-led planning process that recommended 127 sites in 2011) because of a late government decision that there were still 'gaps and limitations' in scientific evidence (Guardian 2011). As Collins \& Evans (2007) noted, 'science, if it can deliver truth, cannot deliver it at the speed of politics' (p. 1).

In many cases, scientific evidence does not support clearcut conclusions. As Stirling (2010) suggested, scientific uncertainties and differences of view need to be clearly set out for decision-makers so that they can make sophisticated judgements. Evidence should be seen as something that informs policy-makers about options and uncertainties. This is particularly pertinent to conservation problems that are messy and complex, and where there is often disagreement about what conservation is trying to achieve: the baseline against which questions about 'what works' can be asked. In medicine this is relatively simple; the goals of medicine are clearly defined and shared by medical professionals. Despite some calls for it (Child, 2009), there is no equivalent to the Hippocratic Oath for ecosystem managers or conservationists and there is no universally shared set of conservation values (Sandbrook et al., 2010).

Many decisions are, and should be, deliberative, and not based in any automatic way on scientific evidence. As Shaxon (2005, p. 102) noted in the context of UK government policy 'evidence is a necessary, but not a sufficient, condition for any decision-making process': the evidence base is dynamic, and good policy results from the good use of evidence as well as from the quality of the evidence itself. Formal scientific data are often invaluable in reaching conservation decisions but equally often are not sufficient. We need to recognize that decision-makers will decide for themselves which forms and sources of evidence are appropriate. For this reason we are dubious about the idea proposed by Segan et al. (2011) that a dedicated organization should be created to evaluate conservation evidence and provide guidance to decision-makers, based on the model of the UK's National Institute for Health and Clinical Excellence.

The changes in evidence-based conservation that we propose build on developing practice. A shift of language to evidenced-informed policy has been advocated in fields such as social policy, for some of the reasons we have enumerated here (e.g. Nevo \& Slonim-Nevo, 2011). Conservation could usefully follow this lead. The change is subtle, and reflects the obvious importance of the idea that conservation decisions should always be informed by the best information available. At the same time, it has profound implications in that it calls for recognition that conservation science is one source of information among many for decision-makers.

\section{Acknowledgements}

We are grateful to many friends, colleagues and students with whom we have discussed evidence-based conservation, inside and outside seminar rooms, particularly Nigel Leader-Williams, Bhaskar Vira, Bill Sutherland and Ioan Fazey. We are grateful to Dilys Roe and two referees for comments on drafts.

\section{References}

Ad ams, W.M. (2010) Path dependence in conservation. In Trade-offs in Conservation: Deciding What to Save (eds N. Leader-Williams, W.M. Adams \& R.J. Smith), pp. 292-310. Wiley-Blackwell, Oxford, UK. 
Berkes, F. (1999) Sacred Ecology: Traditional Ecological Knowledge and Resource Management. Taylor and Francis, London, UK.

Brooks, J.S., Franzen, M.A., Holmes, C.M., Grote, M.N. \& Borgerhoff Mulder, M. (2006) Development as a Conservation Tool: Evaluating Ecological, Economic, Attitudinal, and Behavioural Outcomes. CEE review 05-014 (SR20). Collaboration for Environmental Evidence, Centre for Evidence Based Conservation, Bangor University, UK.

Brosius, J.P. (1999) Green dots, pink hearts: displacing politics from the Malaysian rain forest. American Anthropologist, 101, 36-57.

Bryant, R.L. (2002) Non-governmental organizations and governmentality: 'consuming' biodiversity and indigenous people in the Philippines. Political Studies, 50, 268-292.

Büscher, B. (2010) Anti-politics as political strategy: neoliberalism and transfrontier conservation in Southern Africa. Development and Change, 41, 29-51.

Cabinet Office (1999) Modernising Government. Cm 4310. HMSO, London, UK.

Child, M.F. (2009) The Thoreau ideal as a unifying thread in the conservation movement. Conservation Biology, 23, 241-243.

Collins, H. \& Evans, R. (2002) The third wave of science studies: studies of expertise and experience. Social Studies of Science, 32, 235-296.

Collins, H. \& Evans, R. (2007) Rethinking Expertise. University of Chicago Press, Chicago, USA.

Conservationevidence.com (2013) FAQ. Http:// conservationevidence.com/faq.php [accessed 25 February 2013].

Dickson, P. \& ADAms, W.M. (2009) Science and uncertainty in South Africa's elephant management debate. Environment and Planning C: Government and Policy, 27, 110-123.

DU Toit, A. (2012) Making Sense of 'Evidence': Notes on the Discursive Politics of Research and Pro-poor Policy Making. Working Paper 21, Institute for Poverty, Land and Agrarian Studies, Bellville, South Africa.

Elgert, L. (2010) Politicizing sustainable development: the coproduction of globalized evidence-based policy. Critical Policy Studies, 3, 375-390.

Fairhead, J. \& Leach, M. (2003) Science, Society and Power: Environmental Knowledge and Policy in West Africa and the Caribbean. Cambridge University Press, Cambridge, UK.

Fazey, I., Salisbury, J.G., Lindenmayer, D.B., Maindonald, J. \& Douglas, R. (2004) Can methods applied in medicine be used to summarize and disseminate conservation research? Environmental Conservation, 31, 190-198.

Fazey, I., Fazey, J., Salisbury, J., Lindenmayer, D.B. \& Dovers, S. (2006a) The nature and role of experiential knowledge for environmental conservation. Environmental Conservation, 33, 1-10.

Fazey, I., Proust, K., Newell, B., Johnson, B. \& Fazey, J.A. (2006b) Eliciting the implicit knowledge and perceptions of onground conservation managers of the Macquarie Marshes. Ecology and Society, 11(1), 25.

Ferguson, J. (1990) The Anti-politics Machine: 'Development', Depoliticization, and Bureaucratic Power in Lesotho. Cambridge University Press, Cambridge, UK.

Fraser, D.J., Coon, T., Prince, M.R., Dion, R. \& Bernatchez, L. (2006) Integrating traditional and evolutionary knowledge in biodiversity conservation: a population level case study. Ecology and Society, 11(2), 4.

GARDNER, C.J. (2012) Social learning and the researcher-practitioner divide. Oryx, 46, 313-314.

Guardian (2011) UK Marine Protection Moves Delayed. 15 November 2011. Http://www.guardian.co.uk/environment/2011/nov/15/ukmarine-protection-delay [accessed 14 June 2012].
Greenhalgh, T. \& Russell, J. (2009) Evidence-based policymaking: a critique. Perspectives in Biology and Medicine, 52, 304-318.

Hagen-Zanker, J., Duvendack, M., Mallett, R. \& Slater, R. (2012) Making systematic reviews work for international development research. Secure Livelihoods Research Consortium. Overseas Development Institute, London, UK.

Hajer, M.A. (1995) The Politics of Environmental Discourse: Ecological Modernization and the Policy Process. Oxford University Press, Oxford, UK.

House of Commons Science and Technology Committee (2006) Scientific Advice, Risk and Evidence Based Policy Making. Seventh Report of Session 2005-2006, Volume I. HMSO, London, UK.

ICSU (2002) Science and Traditional Knowledge: Report from the ICSU Study Group on Science and Traditional Knowledge. International Council for Science. Http://www.icsu.org/ publications/reports-and-reviews/science-traditional-knowledge [accessed 7 October 2012].

Ingold, T. (2000) The Perception of the Environment: Essays on Livelihood, Dwelling and Skill. Routledge, London, UK.

Jasanoff, S., Markle, G.E. Peterson, J.C. \& Pinch, T. (eds) (1995) Handbook of Science and Technology Studies. Sage Publications, Thousand Oaks, USA.

Keeley, J. \& Scoones, I. (2003) Understanding Environmental Policy Processes: Cases from Africa. Earthscan, London, UK.

Krska, J. \& Avery, T. (2011) Do we need citizen medicine? New Scientist, 210, 32-33.

Krueger, T., Page, T., Hubacek, K., Smith, L. \& Hiscock, K. (2012) The role of expert opinion in environmental modelling. Environmental Modelling \& Software, 36, 4-18.

Kunn, T. (1962) The Structure of Scientific Revolutions. University of Chicago Press, Chicago, USA.

Leach, M. \& Mearns, R. (1996) The Lie of the Land: Challenging Received Wisdom on the African Environment. Heinemann/James Currey, London, UK.

Nevo, I. \& Slonim-Nevo, V. (2011) The myth of evidence-based practice: towards evidence-informed practice. British Journal of Social Work, 41, 1176-1197.

OBSERVER (2012) Culling badgers could increase the problem of TB in cattle. 14 October 2012. Http://www.guardian.co.uk/ theobserver/2012/oct/14/letters-observer [accessed 25 February 2013].

Peterson, R.B., Russell, D., West, P. \& Brosius, J.P. (2010) Seeing (and doing) conservation through cultural lenses. Environmental Management, 45, 5-18.

Petticrew, M. \& Roberts, H. (2003) Evidence, hierarchies, and typologies: horses for courses. Journal of Epidemiology and Community Health, 57, 527-529.

Pilgrim, S.E. \& Pretty, J. (2010) Nature and Culture. Earthscan, London, UK.

Pretty, J. (2002) People, livelihoods and collective action in biodiversity management. In Biodiversity, Sustainability and Human Communities: Protecting Beyond the Protected (eds T. O’Riordan \& S. Stoll-Kleeman), pp. 61-86. Cambridge University Press, Cambridge, UK.

Pullin, A.S. \& KNight, T.M. (2001) Effectiveness in conservation practice: pointers from medicine and public health. Conservation Biology, 15, 50-54.

Pullin, A.S. \& Knight, T.M. (2003) Support for decision making in conservation practice: an evidence-based approach. Journal for Nature Conservation, 11, 83-90.

Pullin, A.S., Knight, T.M., Stone, D.A. \& Charman, K. (2004) Do conservation managers use scientific evidence to support their decision-making? Biological Conservation, 119, 245-252. 
Pullin, A.S., Knight, T.M. \& Watkinson, A.R. (2009) Linking reductionist science and holistic policy using systematic reviews: unpacking environmental policy questions to construct an evidence-based framework. Journal of Applied Ecology, 46, 970-975.

Pullin, A.S. \& SAlafSKy, N. (2010) Save the whales? Save the rainforest? Save the data! Conservation Biology, 24, 915-917.

Pullin, A.S. \& Stewart, G.B. (2006) Guidelines for systematic review in conservation and environmental management. Conservation Biology, 20, 1647-1656.

Raymond, C.M., Fazey, I., Reed, M.S., Stringer, L.C., Robinson, G.M. \& Evely, A.C. (2010) Integrating local and scientific knowledge for environmental management. Journal of Environmental Management, 91, 1766-1777.

RoE, E. (1991) Development narratives, or making the best of blueprint development. World Development, 19, 287-300.

Roe, D., Elliott, J., Sandbrook, C. \& Walpole, M. (eds) (2012) Biodiversity Conservation and Poverty Alleviation: Exploring the Evidence for a Link. Wiley-Blackwell, Chichester, UK.

Sabatier, P.A. \& Jenkins-Smith, H.C. (eds) (1993) Policy Change and Learning: An Advocacy Coalition Approach. Westview Press, Boulder, USA.

Sandbrook, C., Scales, I., Vira, B. \& Adams, W.M. (2010) Value plurality among conservation professionals. Conservation Biology, $25,285-294$.

SAnderson, I. (2002) Making sense of 'what works': evidence based policy making as instrumental rationality. Public Policy and Administration, 17, 61-75.

Segan, D.B., Bottrill, M.C., Baxter, P.W.J. \& Possingham, H.P. (2011) Using conservation evidence to guide management. Conservation Biology, 25, 200-202.

SHAXON, L. (2005) Is your evidence robust enough? Questions for policy makers and practitioners. Evidence and Policy, 1, 101-111.

Sheil, D. \& Lawrence, A. (2004) Tropical biologists, local people and conservation: new opportunities for collaboration. Trends in Ecology \& Evolution, 19, 634-638.

Smith, R.J., Verissimo, D., Leader-Williams, N., Cowling, R.M. \& KNight, A.T. (2009) Let the locals lead. Nature, 462, 280-281.

Stewart, G.B., Coles, C.F. \& Pullin, A.S. (2005) Applying evidence-based practice in conservation management: lessons from the first systematic review and dissemination projects. Biological Conservation, 126, 270-278.

Stirling, A. (2010) Keep it complex. Nature, 468, 1029-1031.

Sunderland, T.C.H., SAyer, J.A. \& Hoang, M.H. (2013) Introduction: evidence-based conservation from the Lower Mekong. In Evidence-based Conservation: Lessons from the Lower
Mekong (eds T.C.H. Sunderland, J.A. Sayer \& M.H. Hoang), pp. 3-13. Earthscan, London, UK.

Sutherland, W.J., Pullin, A.S., Dolman, P.M. \& Knight, T.M. (2004) The need for evidence-based conservation. Trends in Ecology \& Evolution, 19, 305-308.

Tengö, M., Kvarnström, M., Malmer, P. \& Schultz, M. (2011) Potentials and Pitfalls in Exchange of Knowledge Systems in Cross-scale Ecosystem Assessments. Report from an Informal Expert Meeting with Representatives of the International Indigenous Forum on Biodiversity (IIFB), EU Experts and Scientists Engaged in TK and IPBES. 21-22 June 2011, Jokkmokk, Sweden. Http://www.dialogueseminars.net/resources/Panama/Reading/C.Knowledge-systems/jokkmokk-report-on-knowledge-systemexchange.pdf [accessed 23 February 2013].

Turnhout, E., Bloomfield, B., Hulme, M., Vogel, J. \& Wynne, B. (2012) Listen to the voices of experience. Nature, 488 , 454-455.

Watson-Verran, H. \& Turnbull, D. (1997) Science and other indigenous knowledge systems. In Handbook of Science and Technology Studies (eds S. Jasanoff, G.E. Markle, J.C. Peterson \& T. Pinch), pp. 115-139. Sage Publications, London, UK.

Waylen, K.A., Fischer, A., McGowan, P.J.K., Thirgood, S.J. \& Milner-Gulland, E.J. (2010) The Effect of Local Cultural Context on Community-based Conservation Interventions: Evaluating Ecological, Economic, Attitudinal and Behavioural Outcomes. CEE review 09-019 (SR80). Collaboration for Environmental Evidence, Centre for Evidence-Based Conservation, Bangor University, Bangor, UK.

West, P. (2005) Translation, value, and space: theorizing an ethnographic and engaged environmental anthropology. American Anthropologist, 107, 632-642.

\section{Biographical sketches}

Chris SANDBRook conducts research on trade-offs between ecosystem services at the landscape scale in developing countries, and on the role of evidence and personal values in shaping the actions of conservation organisations. He also helps to run the Masters in Conservation Leadership at the University of Cambridge, a professional development degree for conservationists with leadership potential from around the world. BILL ADAMS is interested in past, present and future changes in the history and development of conservation policy, and is currently studying the institutional politics of landscape scale conservation, and the interactions between synthetic biology and conservation. 